\title{
Imagem Corporal e Bailarinas Profissionais
}

\author{
Body Image of Professional Ballet Dancers
}

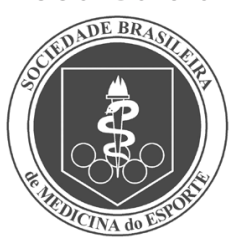

Artigo Original

Aline Nogueira Haas

Anelise Cristina Dias Garcia ${ }^{2}$

Juliana Bertoletti ${ }^{3}$

1. Professora Doutora da Escola

Superior de Educação Física,

Faculdade de Dança, Universidade

Federal do Rio Grande do Sul

(UFRGS), Porto Alegre, RS.

2. Graduada em Educação Física

pela Faculdade de Educação Física

e Ciências do Desporto da Pontifícia

Universidade Católica do Rio Grande

do Sul (PUCRS), Porto Alegre, RS.

3. Graduada em Psicologia pela

Universidade do Vale do Rio dos

Sinos (Unisinos). Especialista em

Psicoterapia de Técnicas Integradas pelo Instituto Fernando Pessoa,

Porto Alegre, RS.

Endereço para correspondência:

Escola Superior de Educação Física, Faculdade de Dança, Universidade

Federal do Rio Grande do Sul

(UFRGS)

Rua Felizardo, 750 - Jd. Botânico 90690-200 - Porto Alegre, RS.

E-mail: alinehaas02@hotmail.com

\section{RESUMO}

A imagem corporal é um tema que sempre está em evidência quando se aborda a dança em suas diferentes modalidades. A busca da imagem corporal ideal em bailarinas vai além dos parâmetros da população em geral e, na medida em que elas se tornam profissionais, a necessidade de manter o peso adequado vai aumentando. Este estudo tem como objetivo verificar o nível de satisfação de bailarinas de balé clássico e de dança jazz com sua imagem corporal, identificando as diferenças e semelhanças entre os dois grupos. Pretende-se ainda identificar semelhanças e diferenças no nível de satisfação com a imagem corporal de bailarinas clássicas de países diferentes. Trata-se de uma pesquisa de campo descritiva. A amostra foi composta por 15 bailarinas adultas profissionais de balé clássico e 16 bailarinas de dança jazz de Porto Alegre, RS, Brasil, e por nove bailarinas adultas profissionais radicadas em Nova lorque, Estados Unidos. O instrumento utilizado para avaliar o nível de satisfação com a imagem corporal foi o Questionário de Imagem Corporal - BSQ, que mede o grau de preocupação com a forma do corpo, a autodepreciação devido à aparência física e a sensação de estar gordo. Os dados foram analisados com auxílio do programa estatístico SPSS 15.0. Para a comparação dos dados foram aplicados os testes Qui-quadrado e Anova, sendo considerados significativos valores de $p<0,05$. Os resultados encontrados mostram que as bailarinas, independente de sua modalidade de escolha, apresentam níveis de insatisfação e distorção de sua imagem corporal. Não houve diferenças estatisticamente significativas $(p=0,96)$ entre os três grupos avaliados. Destaca-se, em conclusão, a importância de estudos sobre imagem corporal em grupos considerados de risco, visando a identificação de distúrbios graves em concomitância com transtornos do comportamento alimentar, que trazem consequências nocivas para a saúde de bailarinas.

Palavras-chave: balé clássico, dança jazz, imagem corporal, bailarinas.

\begin{abstract}
Body image is an issue that is always in evidence when addressing different types of dance. The search for the ideal body image among dancers goes beyond the parameters of the general population and, as they become professionals, the need to maintain the appropriate weight increases. This study aims to verify the level of satisfaction of classical ballet dancers and jazz dancers with their body image, identifying differences and similarities between the two groups. Furthermore, similarities and differences in the level of satisfaction with body image of classical dancers of different countries will be identified. This is a descriptive research. The sample was composed of 15 professional adult ballet dancers and 16 jazz dancers from Porto Alegre, RS, Brazil, and nine professional adult dancers working in New York, United States. The instrument used to assess the level of satisfaction with body image was the Body Shape Questionnaire - BSQ, which measures the degree of concern with the body shape, self-depreciation due to physical appearance and the feeling of being overweight. Data were analyzed with the statistical program SPSS 15.0. Chi-square test and ANOVA test were applied for data comparison and $p<0.05$ values were considered significant. The findings show that the dancers, regardless of their modality of choice, present levels of dissatisfaction and distortion of their body image. There were no statistically significant differences $(p=0.96)$ in the three groups evaluated. In conclusion, studies about body image in risk groups are important for the identification of serious disturbs in concomitance with eating disorders, which bring deleterious consequences to the health of dancers.
\end{abstract}

Keywords: classical ballet, jazz dance, body image, dancers. 


\section{INTRODUÇÃO}

A imagem corporal é entendida como a forma pela qual o corpo se apresenta para a própria pessoa, ou seja, ela é vista de acordo com o que pensamos dela, levando em conta fatores ambientais, emocionais, sociais e outros formadores de opinião(1). Diferentes situações vão modificando a própria imagem corporal e a dos outros, em um processo dinâmico, resultante de memórias e também de percepções presentes. Assim, a imagem corporal vai sendo formada a partir das nossas vivências, ligadas às experiências de terceiros com seus próprios corpos ${ }^{(2)}$.

Na cultura ocidental, ser magra significa não apenas ter um corpo magro, e sim, competência, sucesso, autocontrole e ainda ser atraente sexualmente. As profissões que demandam uma estética corporal adequada, como modelos, bailarinas e atletas, apresentam maior incidência de casos de insatisfação corporal, o que pode levar ao desenvolvimento de transtornos alimentares ${ }^{(3)}$. Ainda não está esclarecido, entretanto, se o ambiente teria uma influência como desencadeante ou se as pessoas já predispostas a desenvolver transtornos alimentares tenderiam a procurar tais profissões ${ }^{(4)}$.

Pode-se dizer que a busca da imagem corporal ideal em bailarinas vai além dos parâmetros da população em geral e, na medida em que elas se tornam profissionais, a necessidade de manter o peso adequado vai aumentando(5). A partir deste contexto, este estudo se justifica pelo fato das bailarinas profissionais representarem um grupo cuja atividade envolve treinamento físico constante, no qual a demanda por um padrão estético adequado pode levar à insatisfação e distorções na sua relação com a imagem corporal. A dança trabalha diretamente com o corpo, e é através do corpo que a bailarina vivencia diferentes emoções e transmite a estética da coreografia. Sua imagem corporal, portanto, está sempre em evidência e faz parte de sua rotina(6).

Este estudo tem como objetivo verificar o nível de satisfação de bailarinas de balé clássico e de dança jazz com sua imagem corporal, identificando as diferenças e semelhanças entre os dois grupos. Pretende-se ainda identificar semelhanças e diferenças no nível de satisfação com a imagem corporal de bailarinas clássicas de Porto Alegre e de Nova lorque. Para melhor entender a influência dos estilos de dança na preocupação das bailarinas com sua imagem corporal, faz-se necessário caracterizar brevemente as modalidades de balé clássico e da dança jazz.

O balé clássico é uma forma de dança ensinada no mundo inteiro seguindo os princípios estabelecidos desde a criação da Academia Real de Dança, fundada por Luis XIV no ano de 1661. A música clássica, o professor, a estrutura da aula e o conteúdo sistemático fazem com que o aluno praticante de balé precise de muita concentração e disciplina durante a aula ${ }^{(7)}$. A rotina do balé clássico visa o treinamento com ênfase na sustentação, equilíbrio, sapatilhas de ponta e um corpo magro, o que está internalizado pelos bailarinos nos dias de hoje, apesar de não existirem dados científicos de que para dançar é necessário ser magro ${ }^{(6)}$.

A dança jazz originou-se da cultura africana, mas foi mesmo reconhecida a partir de 1902, tendo destaque em grandes musicais da Broadway. Gradativamente, a dança jazz tornou-se a fusão de vários estilos de dança, inclusive do balé clássico, com passos específicos, piruetas, saltos e flexibilidade de uma maneira mais rápida e precisa ${ }^{(8)}$. Esta modalidade de dança procura explorar novos movimentos tendo como base o improviso, ou seja, não existem normas e rigor estético, e sim, características individuais dos coreógrafos, diferente do balé clássico que segue um padrão técnico internacional. Assim, a bailarina de jazz possui maior liberdade, desde a maneira de se vestir até a sua movimentação, o que pode influenciar na sua imagem corporal.

\section{MÉTODOS}

Este estudo se caracterizou por ser uma pesquisa de campo descritiva. A amostra teve como critérios de inclusão o tipo de dança praticado, o sexo, o tempo de prática (ser profissional) e a participação voluntária. Participaram da amostra 15 bailarinas pertencentes a grupos profissionais de balé clássico de Porto Alegre, 16 bailarinas pertencentes a grupo de dança jazz de Porto Alegre, e nove bailarinas profissionais radicadas em Nova lorque, Estados Unidos. Todas as bailarinas consentiram a sua participação no estudo através da assinatura do Termo de Consentimento Livre e Esclarecido, que continha as informações necessárias sobre a pesquisa (objetivos, características, explicações sobre a mesma e esclarecimentos). Para as bailarinas norte-americanas foi concebido o mesmo termo de consentimento traduzido para a língua inglesa.

O instrumento usado para avaliar a insatisfação com a autoimagem corporal foi o questionário Body Shape Questionnaire - BSQ (Questionário de Imagem Corporal), que mede o grau de preocupação com a forma do corpo, a autodepreciação devido à aparência física e a sensação de estar gordo. O BSQ foi traduzido por Cordás e Neves ${ }^{(9)}$ e validado para uma população de universitários brasileiros. O questionário distingue dois aspectos específicos da imagem corporal: a exatidão da estimativa do tamanho corporal e os sentimentos em relação ao corpo (insatisfação ou desvalorização da forma física). O instrumento consta de 34 questões com seis opções de respostas: 1 - nunca, 2 - raramente, 3 - às vezes, 4 - frequentemente, 5 - muito frequente, e 6 - sempre. Para as bailarinas norte-americanas foi aplicado o questionário na sua versão original da língua inglesa, o Body Shape Questionnaire.

A classificação dos resultados foi feita pelo total de pontos obtidos e reflete os níveis de preocupação com a imagem corporal. Obtendo o resultado menor ou igual a 80 pontos, é constatado padrão de normalidade e tido como ausência de distorção da imagem corporal. Resultados entre 81 e 110 pontos são classificados como leve distorção da imagem corporal, e entre 111 e 140 pontos são classificados como moderada distorção da imagem corporal; acima de 140 pontos, a classificação é representada como grave distorção da imagem corporal(10).

Os dados também foram analisados com auxílio do programa estatístico SPSS 15.0. Foram calculados os valores de média e desvio padrão, mediana, percentis mínimo e máximo da amostra estudada, assim como os percentuais de respostas obtidos em cada uma das classificações do instrumento BSQ. A variável BSQ contínua, equivalente à escala de valores encontrados nas respostas do teste, foi apresentada com média e desvio padrão. A variável BSQ categórica, representada pelas diferentes classificações do teste, foi apresentada com frequências absolutas e relativas. A variável contínua foi comparada entre os três grupos com o teste de Anova, que foi escolhido por tratar de três grupos diferentes para as análises e por apresentar uma variável contínua com distribuição normal. A variável categórica foi comparada entre os três grupos com o teste do Qui-quadrado, por serem grupos independentes e as informações pertencerem a uma categoria apenas, e também por haver mais de cinco participantes em cada grupo, tendo o teste como princípio básico comparar proporções e ver possíveis divergências. Em ambos os testes foram considerados significativos valores de $p<0,05$.

\section{RESULTADOS}

A tabela 1 mostra o somatório de pontos obtidos no BSQ incluindo média e desvio padrão de cada grupo, o número de participantes (n), e também o número de participantes de cada grupo em determinada classificação e sua respectiva percentagem.

Ainda que exista diferença na classificação entre o grupo de balé clássico de Porto Alegre e Nova lorque e entre estes e o grupo de dança jazz (tabela 1), verificou-se através do teste de Anova que a imagem corporal de bailarinas clássicas e bailarinas da dança jazz não apresentam diferenças estatisticamente significativas (valor de $p=0,96$ ). 
Tabela 1. Somatório de pontos obtidos no BSQ e classificação (média e desvio padrão dos três grupos).

\begin{tabular}{|c|c|c|c|c|c|}
\hline Grupo & $\begin{array}{c}\text { Média } \pm \\
\text { DP }\end{array}$ & $\begin{array}{c}\text { Normal } \\
\mathrm{n}(\%)\end{array}$ & $\begin{array}{l}\text { Leve } \\
\mathrm{n}(\%)\end{array}$ & $\begin{array}{c}\text { Moderado } \\
\mathrm{n}(\%)\end{array}$ & $\begin{array}{l}\text { Grave } \\
\mathrm{n}(\%)\end{array}$ \\
\hline Clássico - POA ( $n=15)$ & $79,9 \pm 28,6$ & $9(60,0 \%)$ & $4(26,7 \%)$ & $1(6,7 \%)$ & $1(6,7 \%)$ \\
\hline $\begin{array}{c}\text { Jazz } \\
(n=16)\end{array}$ & $82,2 \pm 20,4$ & $7(43,8 \%)$ & $7(43,8 \%)$ & $2(12,5 \%)$ & 0 \\
\hline $\begin{array}{c}\text { Clássico - Nl } \\
(\mathrm{n}=9)\end{array}$ & $80,0 \pm 22,0$ & $4(44,4 \%)$ & $5(55,6 \%)$ & 0 & 0 \\
\hline
\end{tabular}

Verifica-se no gráfico 1 que, no grupo de balé clássico de Porto Alegre, a mediana encontrada aparece com o valor de 75 pontos, caracterizando este grupo, na classificação do teste $\mathrm{BSQ}$, como grau de normalidade para insatisfação corporal e distorção de imagem. No percentil de 25\% encontra-se o valor de 63 pontos, significando que, nesse grupo, 75\% das respostas são igual ou maior que esse valor. No percentil 75\% obteve-se o valor de 90 pontos, significando que 25\% da amostra está na classificação leve, moderada e grave. Também podese observar neste gráfico, na parte que representa o balé clássico de Porto Alegre, que ocorreu outliers, que significa que o resultado do valor máximo apresenta um grande afastamento da mediana, por isso no gráfico consta somente o valor referente a $25 \%$ acima do percentil $75 \%$. Optou-se por não retirar estes outliers no momento da análise dos dados, pelo tamanho da amostra.

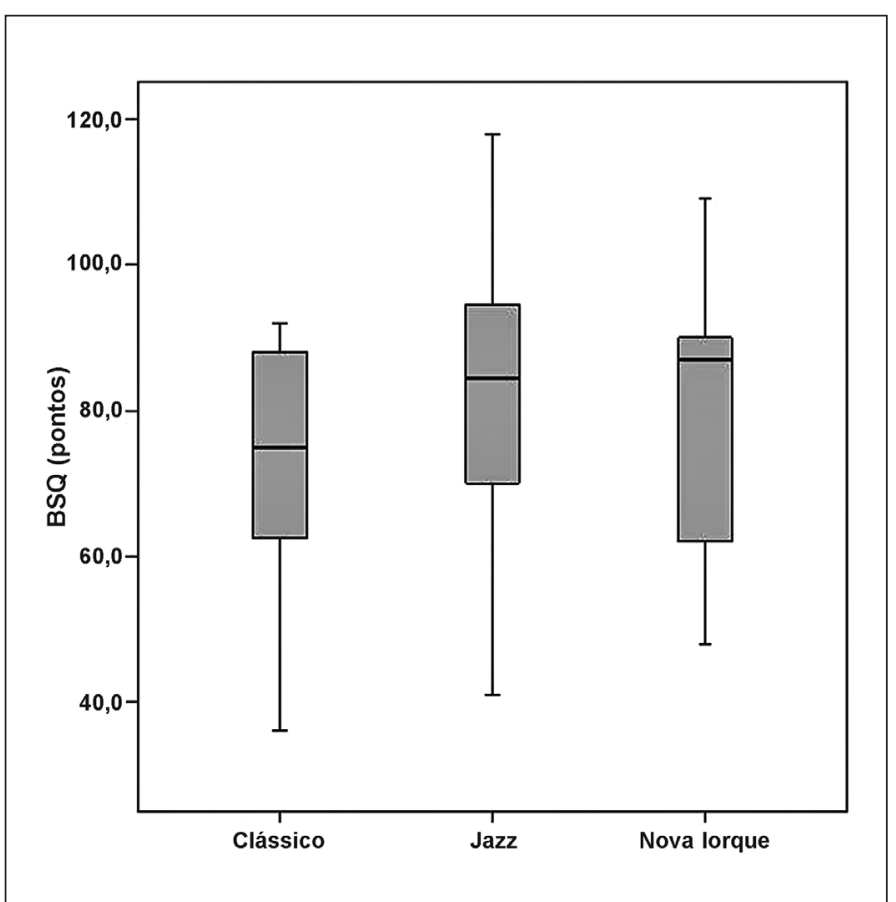

Gráfico 1. Mediana, percentis e valor máximo e mínimo da variável (contínua) dos três grupos.

O grupo da dança jazz apresenta a mediana de 84,5 pontos, mostrando que este valor está enquadrado na classificação do teste BSQ como leve insatisfação e distorção de imagem, diferentemente do balé clássico de Porto Alegre (gráfico 1). O percentil 25\% apresenta o valor de 70 pontos e está próximo a mediana do grupo de balé clássico de Porto Alegre, mostrando que $75 \%$ da amostra encontra-se com valor igual ou superior a 70 . O percentil 75\% tem valor de 94,5 pontos, que é o maior dos três grupos, mostrando que existe mais de 50\% do grupo classificado com leve e moderada insatisfação e distorção de imagem corporal.
O grupo de balé clássico de Nova lorque foi o que apresentou o valor da mediana maior, com 87 pontos, classificado com grau leve de distorção da imagem corporal (gráfico 1). O percentil 25\% foi de 62 pontos, sendo o menor dos três grupos, classificando-se no grau de normalidade. O percentil 75\% foi de 90 pontos, demonstrando que a mediana deste grupo está mais próxima do valor do percentil 75\%, fazendo com que o grupo apresente mais de 50\% da amostra para a classificação leve, afirmada pelo valor máximo encontrado de 109 pontos.

Destaca-se, mais uma vez, que não foram encontradas diferenças estatisticamente significativas entre os três grupos estudados, ainda que existam diferenças de valores de somatório de pontos na média, mediana, mínimo, máximo e percentis, determinando nos mesmos classificações diferentes de percepção da imagem corporal.

\section{DISCUSSÃO}

Dentre os três grupos estudados (balé clássico de Porto Alegre, dança jazz de Porto Alegre e balé clássico de Nova lorque), observouse níveis de insatisfação e distorção da imagem corporal, não havendo diferenças significativas entre eles (valor de $p<0,05$ ). Os resultados mostram que, independente da modalidade, qualquer manifestação artística na forma de dança traz consigo a preocupação do bailarino com sua estética corporal, levando-o a buscar sempre um corpo magro(6).

Não foi encontrado na literatura nenhum estudo que comparasse a imagem corporal de bailarinas de balé clássico com as da dança jazz, mas a área das ciências do movimento tem cada vez mais se dedicado a estudar aspectos relacionados à saúde e ao desempenho atlético em diferentes modalidades de dança e exercício. Em pesquisa realizada por Grego et al.(11), com 83 jovens de 12 a 17 anos, foi realizada avaliação da capacidade física de três grupos distintos, compostos por bailarinas clássicas, praticantes de dança sem formação clássica e escolares. Os resultados encontrados apontam que as bailarinas clássicas têm peso corporal, estatura e índice de massa corporal inferiores aos demais grupos, reforçando que a busca pela imagem corporal adequada no balé clássico significa manter um corpo leve e com baixa percentagem de gordura.

A necessidade de manter um padrão corporal apropriado entre bailarinas resulta frequentemente em insatisfação e distorção da imagem corporal, como mostra o estudo de Ravaldi et al. ${ }^{(12)}$, com 110 bailarinas de balé não profissionais e um grupo controle de 59 pessoas na cidade de Florença, Itália. Foram aplicados os testes Bem Sex Role Inventory, the Eating Disorder Examination (EDE), the Body UneasinessTest (BUT) e Beck Depression Inventory, para investigar a relação entre papel de gênero, comportamento alimentar e imagem corporal. Os resultados mostram que as bailarinas possuem escores maiores nos itens que avaliam imagem corporal e comportamento alimentar, comparados ao grupo controle. Com relação ao processo de aquisição do papel de gênero, o estudo concluiu que a cultura do balé em torno do ideal da magreza e a preocupação das bailarinas com a performance poderia reforçar a internalização de características consideradas como tipicamente masculinas.

Outro estudo encontrado na literatura analisou a distorção de imagem corporal entre 10 bailarinas profissionais de uma companhia de balé. Além da aplicação de testes psicológicos, foram realizadas mensurações das dobras cutâneas. Os resultados mostram que as bailarinas estavam dentro do padrão considerado ideal nas suas medidas das dobras cutâneas, mas não estavam de acordo com o seu corpo, concluindo que existe alto índice de distorção de imagem corporal em grupos profissionais de bailarinos ${ }^{(13)}$.

Em relação ao nível de satisfação com a imagem corporal das bailarinas de balé clássico e de dança jazz de Porto Alegre, foi constatado que mais da metade da amostra (60\%) das bailarinas de balé clássico apresentou classificação no teste BSQ no padrão de normalidade (tabela 1). Entretanto, um total de 56,2\% das bailarinas do grupo de dança jazz apresentaram classificação entre leve e moderada de distorção 
de sua imagem corporal no mesmo teste (tabela 1). Apesar de 60\% da amostra de bailarinas de balé clássico ter se enquadrado no nível normal de satisfação corporal, o grupo de balé de Porto Alegre foi o único a apresentar classificação do BSQ em todos os níveis até o grau grave, diferentemente do grupo da dança jazz, em que o grau máximo encontrado foi o moderado.

O balé, além de ser considerado uma modalidade artística, tem sido citado em alguns estudos sobre o comportamento alimentar de atletas entre os esportes que preconizam o baixo peso corporal e supervalorizam a estética ${ }^{(10)}$. As bailarinas representam parte da população de risco para o desenvolvimento de padrões alimentares inadequados, que podem trazer como consequência prejuízos graves à saúde, entre eles a amenorreia, osteoporose, aneroxia nervosa e bulimia nervosa. Sabe-se que o distúrbio de imagem corporal é considerado um dos principais sintomas nucleares dos transtornos alimentares, caracterizado pela autoavaliação negativa do indivíduo em relação ao seu peso e forma corporal ${ }^{(14)}$. Assim, é de extrema necessidade o esclarecimento de bailarinas e seus professores quanto aos comportamentos de risco, tais como as dietas restritivas para perda rápida de peso, que consequentemente podem levar ao desenvolvimento de quadros graves de Transtornos do Comportamento Alimentar (TCA).

É importante que pais e professores orientem e esclareçam quaisquer dúvidas que possam surgir nas bailarinas desde a sua formação, criando um ambiente propício e estimulante ao aprendizado através da arte, com disciplina e respeito ao desenvolvimento físico e emocional da bailarina de acordo com sua faixa etária ${ }^{(15)}$. Cada vez mais a medicina da dança, como subespecialidade médica, tem-se firmado em países europeus, americanos e soviéticos, onde as grandes escolas e companhias de dança trabalham conjuntamente com diversos profissionais da área da saúde, para atender aos aspectos de aprimoramento físico e psíquico dos bailarinos.

Esta nova especialidade surgiu a partir da necessidade crescente de se investigar cientificamente os benefícios (ritmo, coordenação, flexibilidade, entre outros) e danos (lesões corporais, problemas posturais e nutricionais), que a prática sistemática da dança pode ocasionar. Entretanto, ainda existem muitos profissionais da dança que desconhecem os postulados básicos da biomecânica do corpo e das etapas de um treinamento adequado, conhecimento esse necessário para encontrar a maneira mais correta de trabalhar e/ou ensinar a técnica da dança ${ }^{(16)}$.

Com relação aos danos no aspecto nutricional de bailarinas em formação, uma pesquisa realizada com 546 mulheres universitárias na Universidade de Midwestern revelou que aquelas que dançavam na infância apresentaram características em comum nos questionários aplicados, relacionando comportamento alimentar, depressão, autoestima e imagem corporal. Os resultados mostram que as mulheres que dançavam em idade infantil têm características marcantes para distúrbios alimentares, apresentando maior tendência à magreza e a não controlar impulsos

\section{REFERÊNCIAS}

1. Maturama L. Imagem Corporal: noções e definiçōes. Efdeportes [periódico na Internet]. 2004 abr. Disponível em: http://www.efdeportes.com/efd71/imagem.htm. Acesso em: 15 mar.2008.

2. Schilder P. A imagem do corpo - As energias construtivas da psique. São Paulo: Martins Fontes, 1999.

3. Vieira J, Oliveira L, Vieira L, Vissoci J, Hoshino E, Fernandes S. Distúrbios de Atitudes Alimentares e sua Relação com a Distorção da Auto-Imagem Corporal em Atletas de Judô do Estado do Paraná. R da Educação Física / UEM. [periódico na Internet] 2006;17: [cerca de 7 p]. Disponível em: http://www.periodicos.uem.br/ojs/index. php/RevEducFis/article/view/3338/2411>. Acesso em: 13 mar. 2008.

4. Morgan CM, Vecchiatti IR, Negrão AB. Etiologia dos transtornos alimentares: aspectos biológicos, psicológicos e sócio-culturais. Rev Bras Psiquiat 2002;24:18-23.

5. Fração VB, Vaz MA, Ragasson CP, Müller JP. Efeito do treinamento na aptidão física da bailarina clássica. Movimento [periódico na Internet] 1999 fev. Disponível em: >. Acesso em: 04 nov. 2007.

6. Simas JN, Guimarăes AC. Ballet Clássico e Transtornos Alimentares. R da Educação Física / UEM. [periódico na Internet] 2002; 13(2): [cerca de 7p.]. Disponivel em: http://www.periodicos.uem.br/ojs/index.php/RevEducFis/ article/view/3709/2550. Acesso em: 13 mar 2008.

7. Minden EG. The Ballet Companion. New York: Fireside, 2005.

8. Garcia A, Haas AN. Ritmo e Dança. Canoas: Ed Ulbra, 2006.

9. Cordás TA, Neves JEP. Escalas de avaliação de transtornos alimentares. Rev de Psiq Clin 1999;26:41-7. alimentares $^{(17)}$. Constatou-se também tendência ao perfeccionismo e menor massa corporal em mulheres que já dançaram, evidenciandose que a ênfase na disciplina e estética corporal adequada para dançar desperta e/ou acentua certas características nas meninas praticantes de dança, que as acompanham até a idade adulta.

As bailarinas clássicas dos dois países apresentaram médias e desvios padrão próximos, aproximando-as das semelhanças de relações dos grupos quanto a sua imagem. Assim, pode-se acreditar que não importa onde o balé clássico está sendo trabalhado, ele traz consigo maneiras universais de viver a dança, baseados em princípios estabelecidos desde a sua criação(18). A imagem da sílfide ${ }^{(11)}$, que ganhou notoriedade durante o Romantismo e tornou-se símbolo do balé clássico neste período, parece ser ainda uma referência para as bailarinas clássicas na atualidade, diferente da dança jazz e outros estilos de dança que surgiram posteriormente, influenciados por elementos provenientes de culturas diversas.

É importante destacar ainda que a evolução das técnicas de treinamento em dança possibilitam o desenvolvimento de vários componentes físicos na prática das bailarinas, tornando-as mais ágeis e atléticas para executar movimentos que necessitam tanto de flexibilidade quanto de força muscular. Tais componentes, como a composição corporal, a função motora, a função cardiorrespiratória e a muscular (19), são melhor desenvolvidos e mantidos quando a bailarina possui bons hábitos de saúde, incluindo dieta equilibrada para suprir o consumo energético decorrente do treinamento. Assim, estudos que avaliam a satisfação corporal em grupos de bailarinos e atletas são de grande importância para diagnosticar quando os aspectos psicológicos interferem na percepção da autoimagem nesses profissionais, levando-os a adotar comportamentos alimentares inadequados e nocivos à sua saúde.

\section{CONCLUSÕES}

Considera-se de extrema relevância a realização de mais pesquisas nesta área, já que existem poucos trabalhos publicados relacionando imagem corporal e dança, tanto no Brasil quanto em outros países. É importante que os resultados encontrados nesta pesquisa mostrem que as bailarinas, independente de sua modalidade de escolha, apresentam níveis de insatisfação e distorção de sua imagem corporal. Uma amostra maior poderia confirmar os dados já encontrados neste estudo e na literatura, em termos de significância estatística. Destaca-se, também, a importância de estudos sobre imagem corporal em grupos considerados de risco, visando a identificação de distúrbios graves em concomitância com transtornos do comportamento alimentar, que trazem sérias consequências para a saúde das bailarinas.

Todos os autores declararam não haver qualquer potencial conflito de interesses referente a este artigo.
10. Oliveira FP, Bosi MM, Vigário OS, Vieira RS. Comportamento alimentar e imagem corporal em atletas. Rev Bras Med Esporte 2003;9:348-56

11. Grego, LG, Monteiro HL, Gonçalves A, Padovani CR. Aptidăo física e saúde de praticantes de dança e de escolares. Salusvita 2006;25:81-96.

12. Ravaldi C, Vannacci A, Bolognesi E, Mancini S, Faravelli C, Ricca V. Gender role, eating disorder symptoms, and body image concern in ballet dancers. J Psychosom Res 2006;61:529-35.

13. Pierce EF, Daleng ML. Distortion of body image among elite female dancers. Percept Mot Skills 1998;87:767-70. 14. Saikali CJ, Soubhia CS, Scalfaro BM, Cordás TA. Imagem corporal nos transtornos alimentares. Rev Psiq Clin 2004;31:164-6.

15. Royal Academy of Dancing. Curso de Balé: Guia ilustrado para aprender balé. São Paulo: Ed Martins Fontes, 1998. 16. Haas, AN. Estúdio morfométrico comparativo entre ninas practicantes de danza de una ciudad española y ninas practicantes de danza de una ciudad brasileña [tese]. Cádiz (Espanha): Universidad de Cádiz; 1999.

17. Ackard DM, Henderson JB, Wonderlich AL. The associations between childhood dance participation and adult disordered eating and related psychopathology. J Psychosom Res 2004;57:485-90

18. Medova ML. A Dança Clássica. Lisboa: Ed. Estampa, 1998.

19. Prati SR, Prati AR. Níveis de aptidão física e análise de tendências posturais em bailarinas clássicas. Rev Bras de Cineant Des Hum 2006;8:80-7. 